Research Article

\title{
Physicochemical and Functional Potential of Hydrocolloids Extracted from Some Solanaceae Plants
}

\author{
Kiran Aftab, ${ }^{1}$ Shabana Hameed, ${ }^{1}$ Huma Umbreen, ${ }^{2}$ Shafaqat Ali (iD, ${ }^{3,4}$ Muhammad Rizwan, ${ }^{3}$ \\ Saad Alkahtani $\mathbb{D}^{5}{ }^{5}$ and Mohamed M. Abdel-Daim $\mathbb{D}^{\mathbf{5 , 6}}$ \\ ${ }^{1}$ Department of Chemistry, Government College University, Faisalabad, Pakistan \\ ${ }^{2}$ Institute of Home and Food Sciences, Government College University, Faisalabad, Pakistan \\ ${ }^{3}$ Department of Environmental Sciences and Engineering, Government College University, Faisalabad 38000, Pakistan \\ ${ }^{4}$ Department of Biological Sciences and Technology, China Medical University, Taichung 40402, Taiwan \\ ${ }^{5}$ Department of Zoology, College of Science, King Saud University, P.O. Box 2455, Riyadh 11451, Saudi Arabia \\ ${ }^{6}$ Pharmacology Department, Faculty of Veterinary Medicine, Suez Canal University, Ismailia 41522, Egypt \\ Correspondence should be addressed to Shafaqat Ali; shafaqataligill@gcuf.edu.pk
}

Received 23 February 2020; Revised 23 May 2020; Accepted 4 June 2020; Published 7 July 2020

Academic Editor: Isabel Mafra

Copyright (c) 2020 Kiran Aftab et al. This is an open access article distributed under the Creative Commons Attribution License, which permits unrestricted use, distribution, and reproduction in any medium, provided the original work is properly cited.

\begin{abstract}
Three different plants (Solanum indicum, Solanum surattense, and Solanum nigrum) of Solanaceae family were explored to extract and characterize hydrocolloids in aqueous solution. S. indicum fruit fractions bring in maximum hydrocolloid yield of $21.39 \pm 0.42 \%$ based on $\%$ dry weight of the sample. The observed order of extracting hydrocolloid yield amongst investigating aerial parts of S. surattense, S. nigrum, and S. indicum (\% dry weight) is fruits > stem > leaves. Maximum protein (22\%) and starch $(0.85 \%)$ contents were observed in fruit fractions of S. nigrum and S. indicum, respectively. Among the functional characteristics, the fruit fraction of $S$. indicum has higher water-holding capacity (24.80\%), oil-holding capacity (2.96\%), emulsifying activity (90\%), emulsion stability (70\%), foaming capacity (65\%), and foaming stability (90\%). Monosaccharide profiling results showed the presence of glucose, galacturonic acid, galactose, glucuronic acid, arabinose, and xylose in extracted fractions. The findings propose that hydrocolloids (extracted with water) are cost-effective and would be potential candidate as a substitute for pectin added into foamy and frothy food products and frothy beverages.
\end{abstract}

\section{Introduction}

Based on structure, hydrocolloids relate to hemicelluloses, and on hydrolysis, these form many monosaccharides. The major sources of hydrocolloids are higher plants and animals [1] and these are highly demanded in food and pharmaceutical industries. Hydrocolloids increase the functional characteristics of the product by enhancing various functions like gelling and thickening of solutions, stability of emulsions, foams, and dispersions [2], inhibition of crystal formation, and controlled release of flavors [3].

Among rich plant sources of hydrocolloids, the plants of the family Brassicaceae, Solanaceae, Linaceae, and Plantaginaceae are included. Moreover, the epidermal cells of seed coats contain a large number of complex polysaccharides, i.e., gums and mucilage [4]. The major component of plant hydrocolloid and mucilage is pectin, which is an acidic polysaccharide present in all cell walls and can form gels in the extracellular matrix [5]. Pectin has been shown to have eminent gel-forming, emulsification, and stabilization characteristics along with having possible ability to prevent colon cancer, hyperglycemia, and hypercholesterolemia [6].

In traditional medicine and pharmaceutical industries, different hydrocolloids having various physicochemical characteristics are being used as a sweetening agent and diluents in syrups [7]. Furthermore, Gannasin et al. [1] reported that the use of tamarillo (Solanum betaceum) hydrocolloid in different food and beverages not only enhances water- and oil-holding capacities and emulsifying and foaming characteristics, but also induces bile acid- 
binding and prebiotic activities inside the body. The carboxymethyl cellulose (CMC) is used in syrup and tablet formulations [8], while guar gum along with its derivatives is used as a base for controlled release of different ingredients when administered orally [9].

For the better use of hydrocolloids in food and pharmaceutical industries, it is important to understand their chemical characteristics, structure, and physiological properties. Among plant sources of hydrocolloids, Solanaceae plants are easily available due to their worldwide cultivation. The three selected species of the Solanaceae family, poison berry (Solanum indicum), yellow berried nightshade (Solanum surattense), and black nightshade (Solanum nigrum) are medicinally important and their nutritional properties have been well described, but no such studies are observed about their hydrocolloids. Hence, the current study was an attempt to investigate and characterize the physicochemical properties (oil- and water-holding capacities, emulsification capacity, and stability as well as foaming capacity and stability) of naturally occurring hydrocolloid in the light of commercially available ones. Furthermore, high-performance liquid chromatography (HPLC) was used to find monosaccharide profile of hydrocolloids. Similarly, Fourier transform infrared (FTIR) spectroscopy was employed to explore the chemistry of extracted hydrocolloids. The core objective of the current research work was to explore the natural sources of hydrocolloids for a better use in food processing industries.

\section{Materials and Methods}

2.1. Procurement and Preparation of Samples. Selected plant species of Solanaceae family like poison berry (S. indicum), yellow berried nightshade (S. surattense), and black nightshade (S. nigrum) were gathered from various regions of Punjab province of Pakistan. After rinsing with distilled water, fresh parts including fruit, leaves, and stem from plant samples (500 g each) were homogenized using lab-scale blender (MJ-M176P, Panasonic) for making puree to extract hydrocolloids. All prepared samples (09) had been packaged in falcon tubes and were categorized as S. surattense fruits (SSF), S. surattense stem, (SSS), S. surattense leaf (SSL), S. nigrum fruit (SNF), S. nigrum stem (SNS), S. nigrum leaf (SNL), S. indicum fruit (SIF), S. indicum stem (SIS), and S. indicum leaf (SIL). All samples were stored in a refrigerator (NR-276TE, Japan) at $4^{\circ} \mathrm{C}$ until further investigation.

Undenatured ethanol (95\%) was purchased from $\mathrm{HmbG}$ Chemicals (Hamburg, Germany). All reagents used for proximate analysis were of analytical grade. Agar-agar, bovine gelatin, carboxymethyl cellulose sodium salt (CMC), carrageenan, gum arabic, sodium alginate, and xanthan gum were purchased from R\&M Chemicals (Essex, UK). Gum karaya and pectin from citrus peel (galacturonic acid$\geq 74.0 \%$ ) were purchased from Sigma-Aldrich (St. Louis, MO, USA, and Copenhagen, Denmark), respectively. Starch from wheat and pectin from apples (degree of esterification, 70-75\%) were purchased from Fluka (Steinheim, Germany, and Buchs, Switzerland), respectively. Monosaccharide standards and HPLC grade chemicals used for monosaccharide profiling analysis were purchased from Sigma-Aldrich and Merck (Darmstadt, Germany), respectively.

2.2. Reagents and Solutions. All the chemicals (ethanol (95\%), methanol, and acetonitrile) used for various analyses were of analytical grade and were bought from Merck (Germany). Monosaccharide standards (galactose, glucose, arabinose, mannose, xylose, rhamnose, ribose, fructose, galacturonic acid, and glucuronic acid) were obtained from $\mathrm{BDH}$ (England). Different buffers such as 1-phenyl-3methyl-5-pyrazolone, trifluoroacetic acid, and triethylamine were purchased from Biolabs, Inc. (England). Double-distilled water was used to all aqueous solutions on a fresh basis.

2.3. Extraction of Hydrocolloid. Water-soluble hydrocolloids were extracted from $50 \mathrm{~g}$ dried powdered plant materials in $100 \mathrm{~mL}$ distilled water using a shaking water bath (HH-S, Jiangsu Zhengji Instruments Co. Ltd) for $60 \mathrm{~min}$, at $50 \pm 2{ }^{\circ} \mathrm{C}$ by using the technique elaborated by Yuliarti et al. The extracted hydrocolloids were centrifuged (C0650 in GS-15/ Allegra 21/Allegra X-22 Series, Beckman) for $20 \mathrm{~min}$ at $10,000 \mathrm{rpm}$ and the supernatant was decanted. Remaining hydrocolloids were extracted again using water at $50^{\circ} \mathrm{C}$ in the ratio of $1: 1(\mathrm{w} / \mathrm{v})$ and the sample was centrifuged as described previously. Hydrocolloid precipitation was carried out by combining and stirring the supernatants with $95 \%$ ethanol at $4^{\circ} \mathrm{C}$ for 4 hours. The obtained precipitates were placed in a Petri dish to oven-dry (REX-C700, NS) at $50^{\circ} \mathrm{C}$ and were weighed for hydrocolloid yield until a constant weight was obtained. The hydrocolloid yield of fresh ( $Y f$ ) and dry $(Y)$ weight samples were found out by using mathematical calculations as follows:

$$
\begin{aligned}
Y f(\%) & =100\left[\frac{\text { weight of dried hydrocolloid }(\mathrm{g})}{\text { weight of fresh sample }(\mathrm{g})}\right], \\
Y \% & =\frac{100 Y \mathrm{f}}{100-\text { moisture content }} .
\end{aligned}
$$

2.4. Proximate Composition. According to the AOAC method 934.01 [10], the moisture percentage and dry mass of samples were determined. Ash content was analyzed gravimetrically by ignition of samples $(3 \mathrm{~g})$ in a muffle furnace (1-888-TcMF) at a temperature of $550^{\circ} \mathrm{C}$ for $2 \mathrm{~h}$ (AOAC method no. 930.05) [10]. Kjeldahl method was used to determine protein content with mineralization (KT2 Kjeltabs tablet and a Digestion System 20, 1015 Digester W. Lab. Tec) and distillation (by a Kjeltec Auto Analyser, W. Lab. Tec) using a conversion factor of 5.87 following the AOAC method no. 978.04 [10]. Moreover, the amount of starch in samples was analyzed by Megazyme total starch assay (method 996.11) [10]. The absorbance for each sample and the D-glucose (Merck) control was determined at $510 \mathrm{~nm}$ against the reagent blank.

Dietary fiber was found out by the method of Gannasin et al. [1] using the following calculation: 
dietary fiber $(\%)=100 \%-($ moisture + ash + protein + starch $) \%$.

\subsection{Functional Characteristics of Extracted Hydrocolloid Samples}

2.5.1. Water-Holding (WHC) and Oil-Holding (OHC) Capacity. Water- and oil-holding capacities were determined through the method used by Robertson et al. [11] with certain changes. Each sample $(250 \mathrm{mg})$ was mixed in separate Erlenmeyer flasks with distilled water $(100 \mathrm{~mL})$ and olive oil ( $25 \mathrm{mg} / 10 \mathrm{~mL})$, stirred well, and was left for 1 hour at room temperature. All samples were centrifuged for $10 \mathrm{~min}$ and residues were weighed. Water- and oil-holding capacities were articulated as per $\mathrm{mL}$ of water and per $\mathrm{mL}$ of oil, respectively, and held by each gram of sample.

2.5.2. Foaming Capacity and Stability (FC and FS). One gram of each sample was assorted with distilled water $(100 \mathrm{~mL})$, and samples were homogenized robustly (13000 rpm) for five minutes. The homogenized suspensions were instantly shifted to a graduated cylinder of $250 \mathrm{~mL}$ to measure the volume of foam at different time intervals. The following equations were used to calculate the FC and FS:

$$
\begin{aligned}
& \mathrm{FC} \%=\left(\frac{\text { vol.after }- \text { before homogenization }}{\text { vol.before homogenization }}\right) \times 100, \\
& \mathrm{FS} \%=\left(\frac{\text { foam vol.after time }(t)}{\text { Initial foam vol. }}\right) \times 100 .
\end{aligned}
$$

2.5.3. Emulsifying Activity (EA) and Emulsifying Stability (ES). Emulsification activity and stability of different hydrocolloid samples were calculated according to Chau et al. [12]. Emulsions were primed with standard sunflower oil $(65 \% \mathrm{w} / \mathrm{w})$ through the recipe of Campbell et al. [13]. In $15 \mathrm{~mL}$ graduated tubes, the resulting emulsions were centrifuged at $6000 \mathrm{rpm}$ for 5 minutes, and volumes attained by emulsions were measured. To measure the ES, the emulsions were heated $\left(80^{\circ} \mathrm{C}\right)$ for $30 \mathrm{~min}$ to measure the emulsification stability. The heated samples were further chilled at room temperature and were centrifuged again at $6000 \mathrm{rpm}$ for $5 \mathrm{~min}$. Both EA and ES were calculated using the following equations, respectively:

$$
\begin{aligned}
& \text { emulsification activity }(\%)=\frac{\text { vol.of emulsified layer }(\mathrm{mL})}{\text { vol.of the whole layer in the centrifuge tube }} \\
& \text { emulsification stability }(\%)=\frac{\text { vol.of remaining emulsified layer }(\mathrm{mL})}{\text { vol.of original emulsion }(\mathrm{mL})} \times 100 \text {. }
\end{aligned}
$$

2.6. FTIR Analysis. Functional groups of all samples were also analyzed using a FTIR spectrophotometer (PerkinElmer Spectrum 100 FTIR, USA). The spectrum was recorded in absorbance mode in mid-infrared region with a CsI detector in triplicate from 4,000 to $400 \mathrm{~cm}^{-1}$ and $4 \mathrm{~cm}^{-1}$ resolution.

\subsection{Monosaccharide Profiling Using HPLC.} Monosaccharide profiling was carried out following the protocol of Lv. et al. [14]. The standard solutions of all monosaccharides including samples (10 mg each) were dissolved in $1 \mathrm{M}$ trifluoroacetic acid (TFA) and incubated at $130^{\circ} \mathrm{C}$ for $2 \mathrm{~h}$, and the mixture was centrifuged at $2000 \mathrm{rpm}$ for $5 \mathrm{~min}$ and was evaporated until dried. The samples obtained after dryness were dissolved in $1 \mathrm{~mL}$ distilled water for advance analysis. Derivatization of hydrolyzed samples was carried out with 1-phenyl-3-methyl-5-pyrazolone (PMP), and resultant solutions were incubated at $70^{\circ} \mathrm{C}$ for 60 minutes, evaporated using a rotary evaporator, and proceeded with liquid-liquid separation method. Using the C18 HPLC column, different monosaccharides (galactose, glucose, arabinose, mannose, xylose, rhamnose, ribose, fructose, glucuronic acid, and galacturonic acid) were determined.
2.8. Statistical Analysis. Experiments were conducted in triplicate to get means of these three replicates as a result. The obtained data were analyzed statistically by analysis of variance (ANOVA) using SPSS Inc. (Released 2008. SPSS Statistics for Windows, version 17.0. Chicago: SPSS Inc.). The significance of differences among means of triplicate values was detected using two-way factorial design. To measure the differences $(P<0.05)$ between the means, least significant difference (LSD) post hoc test was applied and values are given as means of triplicate \pm standard deviation.

\section{Results and Discussions}

3.1. Hydrocolloid Yield of Various Plant Parts. The waterextracted hydrocolloid yield ranged from $1.5 \pm 0.02$ to $21.00 \pm 0.42 \%$ of the dry weight of investigated pulp, and no hydrocolloid contents were obtained from the leaf fractions of $S$. indicum even taking a large amount of extract (Table 1). Water was used as an extracting medium because the watersoluble polysaccharides have positive effects on health and can reduce the serum cholesterol concentration [7]. The obtained yield of hydrocolloid ( $Y, \%$ dry weight) from each sample showed that the $S$. indicum fruit showed the maximum hydrocolloid concentration (21.00 $\pm 0.42 \%)$, 
TABLE 1: Hydrocolloid yield and proximate composition (\% age \pm SD) of aerial parts of S. nigrum, S surattense, and S. indicum using the water extraction method.

\begin{tabular}{|c|c|c|c|c|c|c|c|}
\hline Botanical name & Fraction/parts & Yield & Moisture content & Ash content & Protein content & Starch content & Dietary fiber \\
\hline \multirow{4}{*}{ Solanum nigrum } & Fruit & $13.50^{\mathrm{c}} \pm 0.18$ & $11.00^{\mathrm{e}} \pm 0.44$ & $0.70^{c} \pm 0.03$ & $22.00^{\mathrm{a}} \pm 0.41$ & $0.70^{\mathrm{c}} \pm 0.02$ & $66.30^{b c} \pm 1.22$ \\
\hline & Stem & $5.92^{\mathrm{d}} \pm 0.17$ & $19.65^{b} \pm 0.68$ & $0.54^{\mathrm{e}} \pm 0.02$ & $16.00^{c} \pm 0.75$ & $0.65^{\mathrm{d}} \pm 0.01$ & $63.81^{c} \pm 2.66$ \\
\hline & Leaves & $1.50^{\mathrm{f}} \pm 0.02$ & $25.00^{\mathrm{a}} \pm 0.56$ & $0.60^{\mathrm{d}} \pm 0.01$ & $9.00^{\mathrm{d}} \pm 0.38$ & $0.10^{\mathrm{g}} \pm 0.00$ & $65.30^{b c} \pm 2.37$ \\
\hline & & - & $18.55^{\mathrm{A}} \pm 2.06$ & $0.61^{B} \pm 0.03$ & $15.67^{\mathrm{A}} \pm 1.90$ & $0.48^{\mathrm{A}} \pm 0.10$ & $65.14^{\mathrm{B}} \pm 1.15$ \\
\hline \multirow{4}{*}{ Solanum surattense } & $F$ & $17.00^{\mathrm{b}} \pm 0.76$ & $10.0^{\mathrm{ef}} \pm 0.20$ & $0.80^{\mathrm{b}} \pm 0.02$ & $21.50^{\mathrm{a}} \pm 0.57$ & $0.80^{\mathrm{b}} \pm 0.02$ & $66.90^{\mathrm{bc}} \pm 1.76$ \\
\hline & Stem & $6.70^{\mathrm{d}} \pm 0.09$ & $15.50^{\mathrm{d}} \pm 0.51$ & $0.70^{\mathrm{c}} \pm 0.01$ & $17.00^{c} \pm 0.55$ & $0.45^{\mathrm{e}} \pm 0.01$ & $66.35^{\mathrm{bc}} \pm 2.73$ \\
\hline & Leaves & $1.88^{\mathrm{f}} \pm 0.09$ & $20.00^{b} \pm 0.31$ & $0.60^{\mathrm{d}} \pm 0.01$ & $6.00^{\mathrm{e}} \pm 0.12$ & $0.00^{\mathrm{h}} \pm 0.00$ & $73.10^{\mathrm{a}} \pm 1.50$ \\
\hline & & - & $15.17^{\mathrm{B}} \pm 1.46$ & $0.70^{\mathrm{A}} \pm 0.03$ & $14.83^{\mathrm{B}} \pm 2.31$ & $0.42^{\mathrm{B}} \pm 0.12$ & $68.7^{\mathrm{A}} \pm 1.50$ \\
\hline \multirow{4}{*}{ Solanum indicum } & Fruit & $21.00^{\mathrm{a}} \pm 0.42$ & $9.50^{f} \pm 0.43$ & $0.90^{\mathrm{a}} \pm 0.01$ & $19.00^{\mathrm{b}} \pm 0.44$ & $0.85^{\mathrm{a}} \pm 0.01$ & $69.75^{\mathrm{ab}} \pm 1.62$ \\
\hline & Stem & $4.90^{\mathrm{e}} \pm 0.18$ & $18.00^{C} \pm 0.53$ & $0.60^{\mathrm{d}} \pm 0.01$ & $16.50^{c} \pm 0.24$ & $0.30^{\mathrm{f}} \pm 0.01$ & $64.60^{c} \pm 1.30$ \\
\hline & Leaves & $0.00^{\mathrm{g}} \pm 0.00$ & $0.00^{\mathrm{g}} \pm 0.00$ & $0.00^{f} \pm 0.00$ & $0.00^{f} \pm 0.00$ & $0.00^{\mathrm{h}} \pm 0.00$ & $0.00^{\mathrm{d}} \pm 0.00$ \\
\hline & Mean & - & $9.17^{\mathrm{C}} \pm 2.61$ & $0.50^{\mathrm{C}} \pm 0.13$ & $11.83^{C} \pm 2.98$ & $0.38^{C} \pm 0.12$ & $44.78^{C} \pm 11.24$ \\
\hline
\end{tabular}

Each value is expressed as the mean \pm standard deviation $(n=3)$ of a triplicate analysis. The means followed by different superscripted lowercase letters indicate significant differences $(P<0.05)$ within the rows and columns based on ANOVA two-way factorial test. Small letters represent comparison among interaction means, and capital letters are used for the overall mean. ND: not determined.

subsequently S. surattense fruit $(17.00 \pm 0.76 \%)$ and $S$. nigrum fruit $(13.5 \pm 0.18 \%)$. Moreover, the fruit fractions of the plants used in the present study showed a significantly higher percentage yield of hydrocolloids through the water extraction method as compared to the hydrocolloid yield obtained from the gold kiwi fruit (Actinidia chinensis; family, Actinidiaceae) studied by Yuliarti et al. [15]. The obtained hydrocolloid yield ranged from $4.90 \pm 0.18$ to $6.70 \pm 0.09 \%$ in case of stem fractions; however, the percentage yield from leaf fractions was observed to be the lowest compared to other components of investigated plants.

\subsection{Proximate Composition of Water-Extracted Hydrocolloid.} Analyses of proximate composition revealed that the fruit extracts were significantly $(P \leq 0.05)$ higher in protein and dietary fiber contents, whereas the starch content was lower in fruit part (Table 1). The observed orders of moisture and ash contents were leaves $>$ stem $>$ fruit and fruit $>$ stem $>$ leaves, respectively, in extracts of different parts of all the investigated plants irrespective of the species. The maximum moisture content was observed in leaves of $S$. nigrum $(25.00 \pm 0.56 \%)$, and the minimum was observed in $S$. indicum fruit $(9.50 \pm 0.43 \%)$. These results are comparable with the hydrocolloid extracted from tamarillo pulp with $10.65 \%$ of moisture content [1].

The comparison between different parts of plants studied for protein analysis showed a significant difference $(P \leq 0.05)$, with fruits having the highest concentration. The protein contents of fruit fractions of $S$. nigrum, S. surattense, and $S$. indicum were found to be $22.00 \pm 0.41 \%$, $21.50 \pm 0.57 \%$, and $19.00 \pm 0.44 \%$ (w/w, dry weight), respectively, with no significant change at $P \leq 0.05$ (Table 1 ). It is reported that higher protein content affects the quantity and quality of the extracted gum [16]; however, another study explained that the protein concentration of crude gum indicates the occurrence of proteins and enzymes related to structure and may also suggest potential adulteration with seed germ [17].

\subsection{Functional Properties of Different Samples of Hydrocolloid}

3.3.1. Water- and Oil-Holding Capacities of Hydrocolloids. The water-holding capacity (WHC) is described as the milliliters of water held by each gram of dried sample. The overall order of $\mathrm{WHC}$ and $\mathrm{OHC}$ in different parts of investigated plants is fruit $>$ stem $>$ leaf. Among all the three hydrocolloid fruit fractions, a significant difference $(P \leq 0.05)$ was found in WHC, but OHC values were approximately the same (Figure 1). The highest value of the WHC was observed in SIF $(24.80 \pm 0.35 \%)$, followed by SSF $(17.20 \pm 0.28 \%)$ with no significant difference in oil-holding capacity (Figures 1(a) and 1(b)). Similar results were also observed using the gum karaya having 24.39\% WHC and $1.12 \%$ OHC [18]. However, the SNF showed $09.40 \pm 0.38$ and $2.15 \pm 0.52 \% \mathrm{WHC}$ and $\mathrm{OHC}$, respectively, that is in comparison with commercially used apple pectin $(6.71 \%$ WHC and $2.11 \% \mathrm{OHC}$, respectively) [19]. The least value of oilholding capacity was observed for SIL $(1.8 \pm 0.19 \%)$ that is also in comparison with that of carboxymethyl cellulose $(1.58 \%)$ and sodium alginate (1.22\%) [16]. The water-holding capacity was absent in Solanum indicum leaves; similarly, no $\mathrm{OHC}$ was shown by Solanum indicum stem. It has been proven by studies that hydrocolloid with high WHC and $\mathrm{OHC}$ can be used as a fat replacer in low-fat food products and also act as emulsifying agents in food products [19, 20]. Therefore, it is expected that hydrocolloids of $S$. nigrum can be successfully used to provide stability to oil-based emulsions. This stabilization is attained by the formulation of a resilient multimolecular film all around oil globule and thus can hinder the amalgamation of a hydrophilic fence between water and oil segments [8].

3.3.2. Foaming Capacity and Stability of Hydrocolloid. FC of different extracted hydrocolloid samples of S. nigrum, $S$. surattense, and $S$. indicum was investigated at room temperature for an hour (Table 2). The highest values of foaming capacity were observed in $S$. indicum fruit $(65.00 \pm 3.05 \%)$, followed by $S$. surattense fruit 


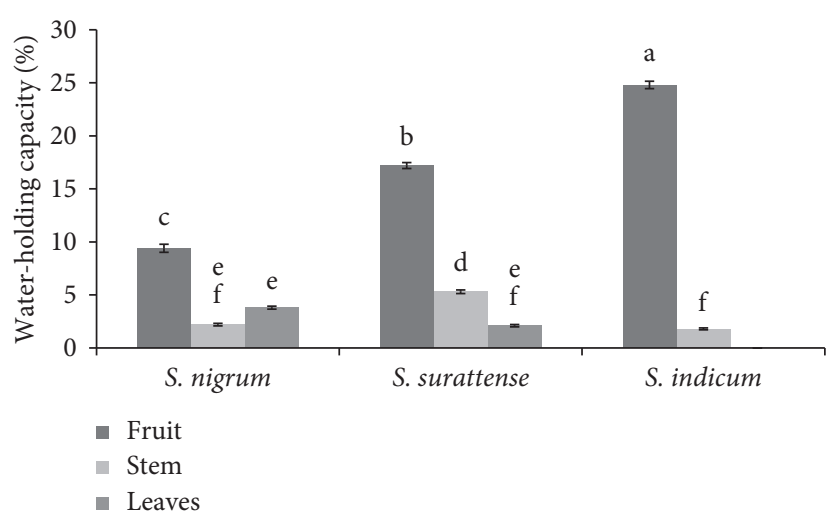

(a)

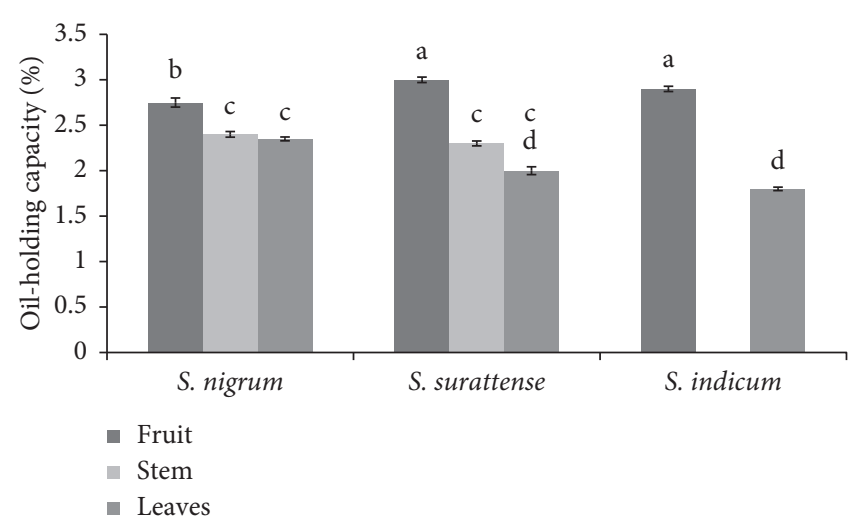

(b)

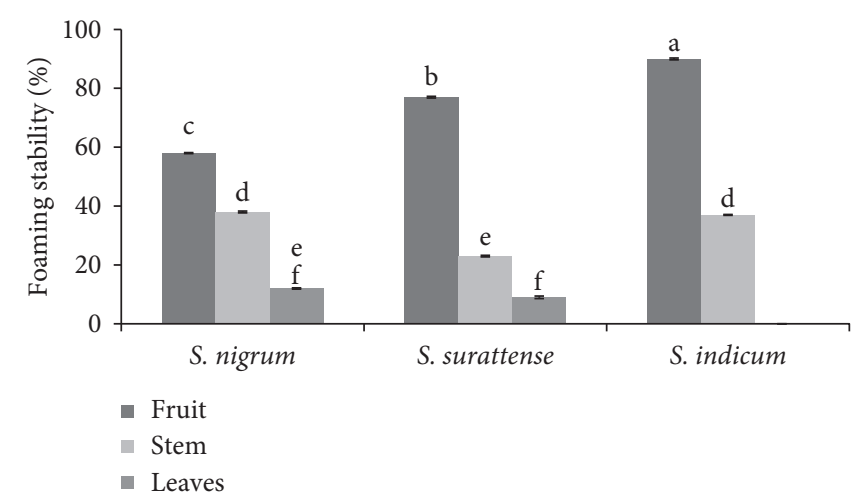

(c)

FiguRE 1: Water-holding capacity (a), oil-holding capacity (b), and foaming stability (c) of extracted hydrocolloid from aerial parts of $S$. nigrum, S. surattense, and $S$. indicum using the water extraction method. ${ }^{\mathrm{a}-\mathrm{f}}$ Different letters on bars show significant difference $(P \leq 0.05)$.

TABLE 2: Foaming capacity, emulsifying activity, and emulsifying stability (\%age \pm SD) of hydrocolloid from aerial parts of $S$. surattense, $S$ nigrum, and $S$ indicum using the water extraction method.

\begin{tabular}{|c|c|c|c|c|}
\hline Botanical name & Fraction/parts & Foaming capacity & Emulsifying activity & Emulsifying stability \\
\hline Solanum nigrum & $\begin{array}{l}\text { Fruit } \\
\text { Stem } \\
\text { Leaves }\end{array}$ & $\begin{array}{c}40.00^{\mathrm{c}} \pm 1.06 \\
25.00^{\mathrm{de}} \pm 0.46 \\
10.00^{\mathrm{f}} \pm 0.27\end{array}$ & $\begin{array}{c}80.00^{\mathrm{b}} \pm 3.7 \\
40.00^{\mathrm{f}} \pm 2.27 \\
50.00^{\mathrm{e}} \pm 1.4\end{array}$ & $\begin{array}{l}60.00^{\mathrm{c}} \pm 0.92 \\
40.00^{\mathrm{d}} \pm 1.97 \\
40.00^{\mathrm{d}} \pm 0.54\end{array}$ \\
\hline Solanum surattense & $\begin{array}{c}\text { Fruit } \\
\text { Stem } \\
\text { Leaves }\end{array}$ & $\begin{array}{l}50.00^{\mathrm{b}} \pm 2.50 \\
35.00^{\mathrm{d}} \pm 0.46 \\
20.00^{\mathrm{e}} \pm 0.77\end{array}$ & $\begin{array}{l}90.00^{\mathrm{a}} \pm 2.52 \\
60.00^{\mathrm{d}} \pm 1.39 \\
70.00^{\mathrm{c}} \pm 1.07\end{array}$ & $\begin{array}{l}0.00^{\mathrm{g}} \pm 0.00 \\
0.00^{\mathrm{g}} \pm 0.00 \\
0.00^{\mathrm{g}} \pm 0.00\end{array}$ \\
\hline Solanum indicum & $\begin{array}{l}\text { Fruit } \\
\text { Stem } \\
\text { Leaves }\end{array}$ & $\begin{array}{c}65.00^{\mathrm{a}} \pm 3.05 \\
30.00^{\mathrm{d}} \pm 0.46 \\
0.00^{\mathrm{i}} \pm 0.00\end{array}$ & $\begin{array}{c}90.00^{\mathrm{a}} \pm 1.86 \\
20.00^{\mathrm{g}} \pm 0.38 \\
0.00^{\mathrm{i}} \pm 0.00\end{array}$ & $\begin{array}{c}70.00^{b} \pm 1.36 \\
30.00^{f} \pm 1.09 \\
0.00^{g} \pm 0.00\end{array}$ \\
\hline
\end{tabular}

Each value is expressed as the mean \pm standard deviation $(n=3)$ of a triplicate analysis. The means followed by different superscripted lowercase letters indicate significant differences $(P<0.05)$.

$(50.00 \pm 2.50 \%)$ and $S$. nigrum fruit $(40.00 \pm 1.06 \%)$. The foaming stability of all the nine samples was studied for a 2hour time interval. The highly stable foam volume up to 2 hours was observed from fruit parts of all investigated plant parts (Figure 1(c)). The maximum value of foaming stability was observed in SIF $(90 \pm 0.31 \%)$, signifying its use as a foam stabilizer in lathered beverages including beer cappuccino. Furthermore, it may also play significant role in foam formation in various food products, such as marshmallows and mousses. The water-extracted hydrocolloids from S. nigrum and $S$. surattense fruits showed intermediate foaming stability of $58.00 \pm 0.17 \%$ and $77.00 \pm 0.28 \%$, respectively, after $2 \mathrm{~h}$ of foam formation. Hydrocolloids from stem parts of the investigated plants showed low foaming stability, while no significant $(P \leq 0.05)$ foaming stability was observed in Solanum indicum leaves having $0.00 \%$ foaming capacity. Earlier studies have reported that sodium alginate and gum arabic show a poor foaming stability, while wheat starch, CMC carrageenan, and xanthan gum have not been analyzed because these hydrocolloids do not show any foaming capacity [1]. However, the methanolic extract of flaxseed mucilage (Linaceae family) showed much higher 


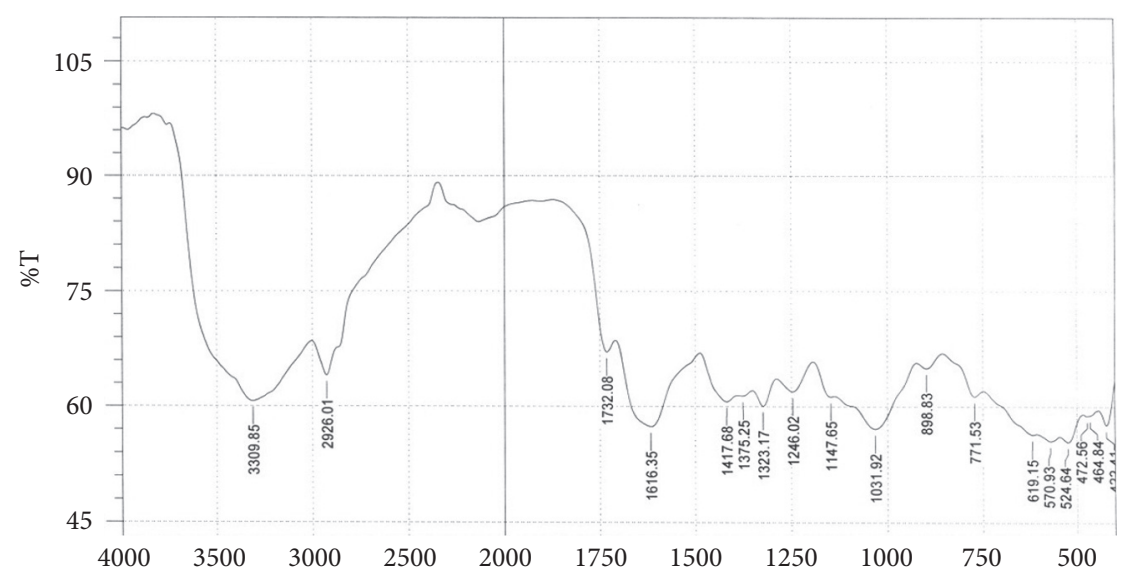

(a)

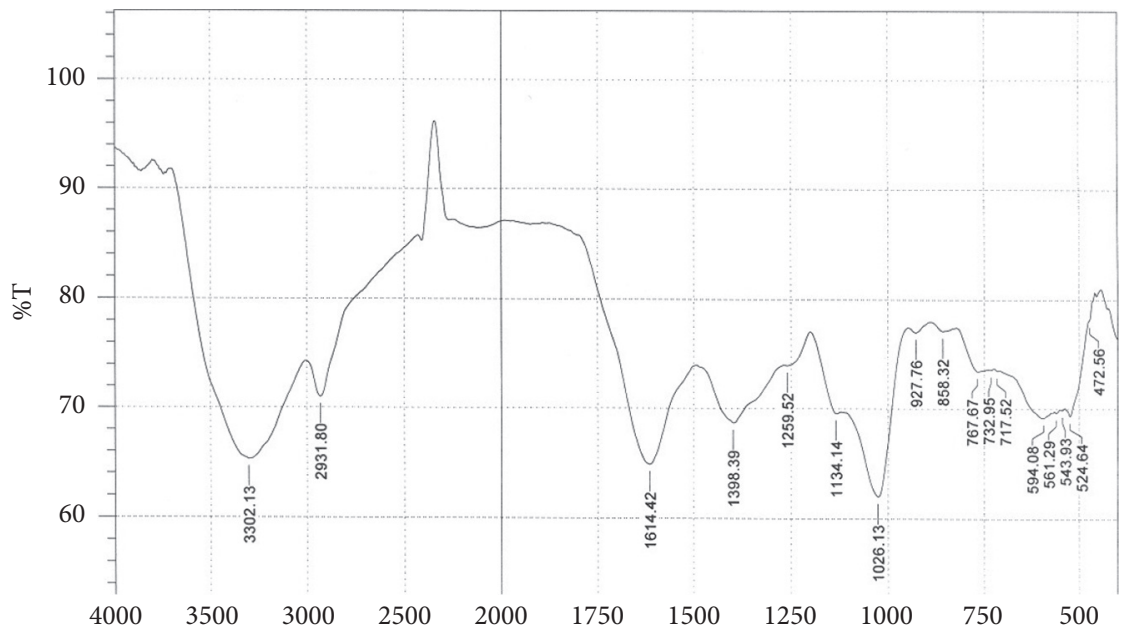

(b)

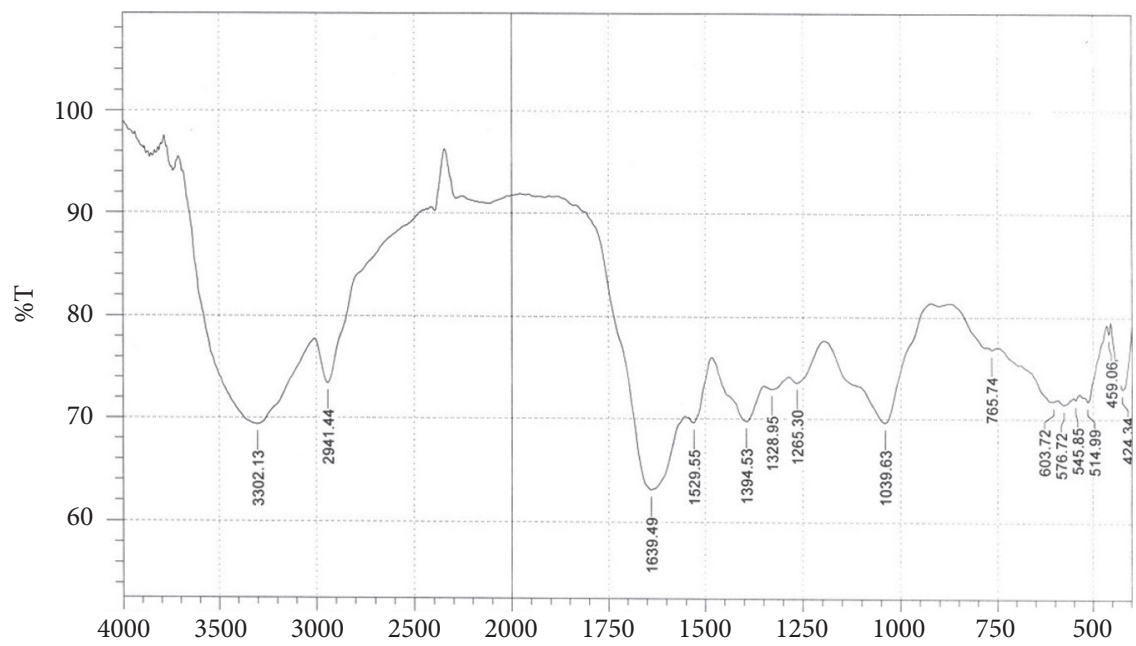

(c)

FIgURE 2: FTIR characterization of hydrocolloid extracted from S. surattense (a), S. nigrum (b), and S. indicum (c).

foaming capacity and stability compared to the present study [21].

3.3.3. Emulsifying Activity and Stability of Hydrocolloid. The samples heated as described in methodology were used for preparing oil-in-water emulsions (65\% oil, w/w). The profile of emulsifying activity and stability was determined by using $2 \%(\mathrm{w} / \mathrm{v})$ of samples of fruit, stem, and leaves of experimental plants. The significantly $(P \leq 0.05)$ higher emulsifying activity and stability range were observed in the fruit fractions of all investigated plants (Table 2). Similarly, Alfredo et al. [22] reported 70\% emulsifying activity in apple 


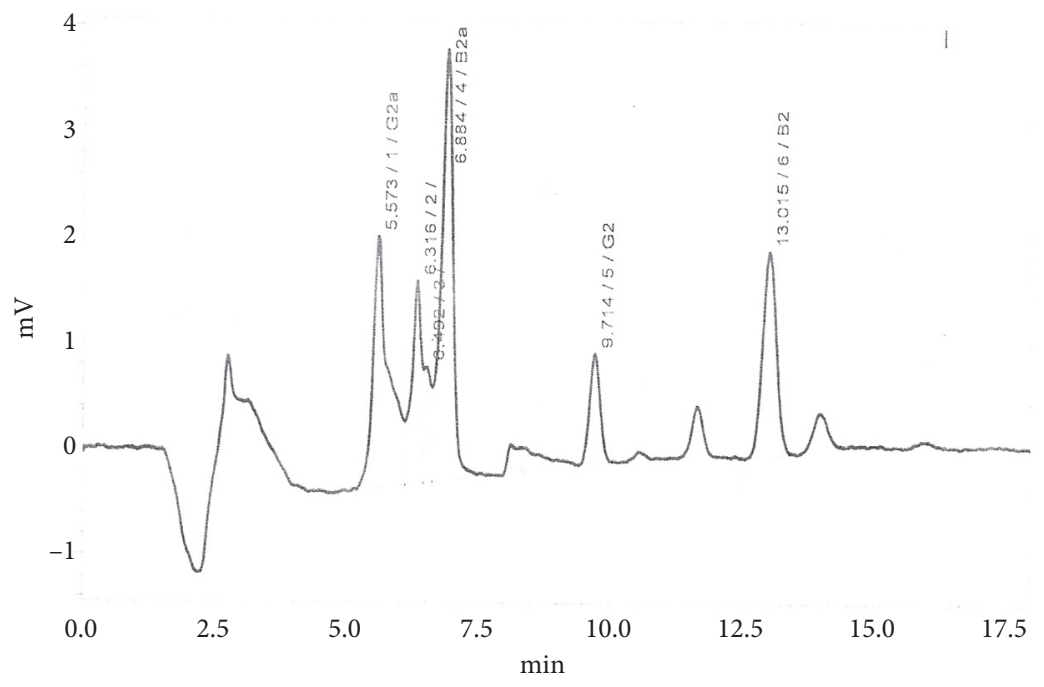

(a)

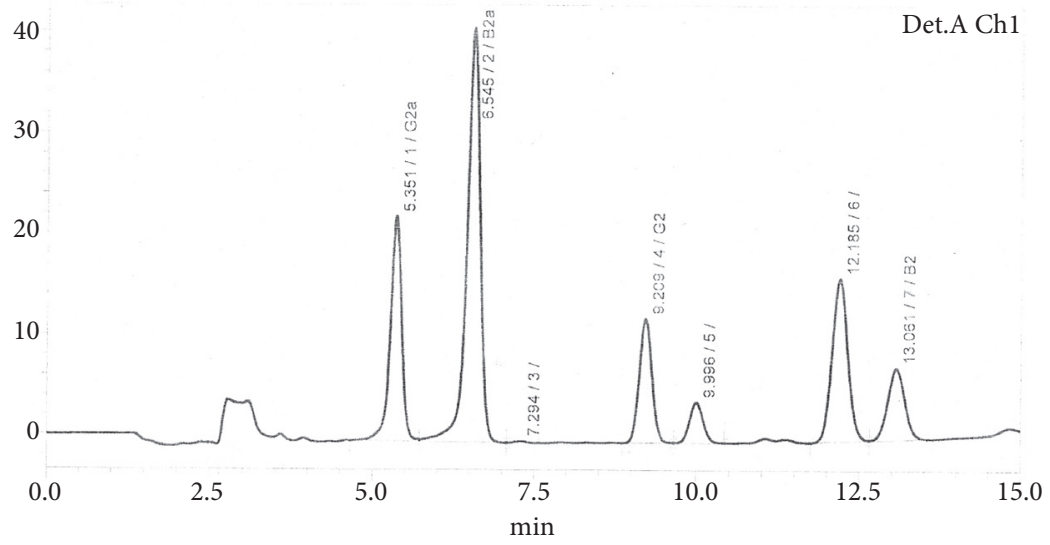

(b)

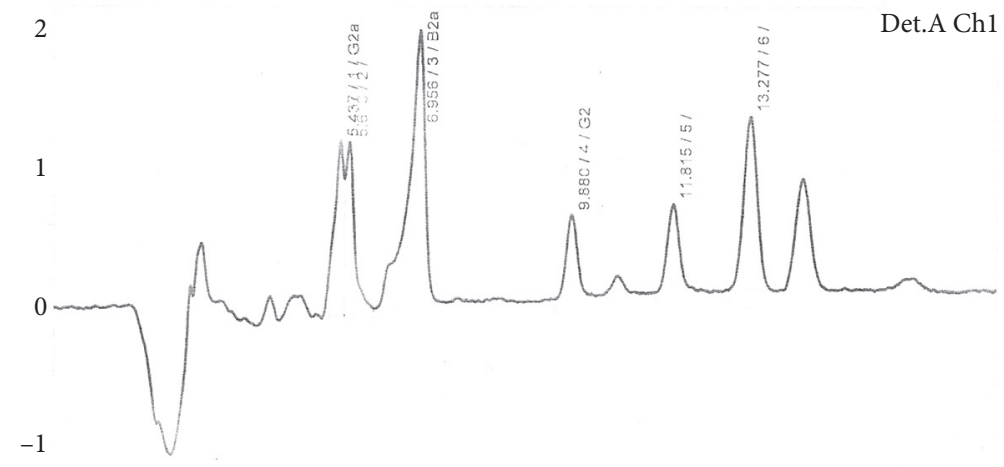

(c)

Figure 3: Reverse-phase HPLC characterization of hydrocolloid extracted from S. surattense (a), S. nigrum (b), and S. indicum (c).

pectin. In the present study, the emulsifying activity of leaves was observed to be $70.00 \pm 1.07 \%$ and $50.00 \pm 1.40 \%$ in SS and $\mathrm{SN}$, respectively. The order of emulsifying activity in stem of all the plants was SS $(60.00 \pm 1.39 \%)>\mathrm{SN}$ $(40.00 \pm 2.27 \%)>$ SI $(20.00 \pm 38 \%)$. Hydrocolloids extracted from stem, leaves, and fruits of S. surattense showed no emulsifying stability. However, according to the literature, apple pectin shows the highest emulsifying stability (90.00\%), but it has low emulsifying activity as compared with hydrocolloid extracted from SIF. Higher emulsifying activity and stability of hydrocolloid especially from fruit fractions investigated in the present study may enhance the 
ability of food products to adsorb bile acids in the intestine and are indicative of its potential use to reduce cholesterol level in blood [22].

3.4. FTIR Analysis. FTIR spectroscopy is a reproducible and quantitative technique to study biomolecules within a short scanning time [23]. The major functional groups of extracted hydrocolloids present in the fruit fractions of $S$. nigrum, $S$. surattense, and $S$. indicum were recognized through FTIR spectra (Figure 2). The functional groups were allocated in accordance with the presence of the absorption bands at their particular wavenumbers $\left(\mathrm{cm}^{-1}\right)$, as $3300(\mathrm{OH}$ stretch $)$, 2941 (C-H stretch of methyl groups), 1745 (C=O stretch of methyl esterified carbonyl), $1630\left(\mathrm{COO}^{-1}\right.$ asymmetric stretch of carboxylate anion, absorption region of amide I proteins), 1529 (amide II from protein), $1432\left(\mathrm{COO}^{-1}\right.$ symmetric stretch of carboxylate anion), $1229\left(\left(\mathrm{CH}_{3}\right)_{3}-\mathrm{C}\right)$, and 1017 (C-O and $\mathrm{C}-\mathrm{C}$ stretch, absorption region of polysaccharides) [6]. The highest absorption configuration between 1300 and $800 \mathrm{~cm}^{-1}$ expressed as the "fingerprint" region showed specificity with respective hydrocolloids. The FTIR spectra of SNF, SSF, and SIF showed "fingerprint" regions same as that of hydrocolloids from citrus, suggesting that these might be from the pectin family. The absorption bands found in all samples were at $3302-3309 \mathrm{~cm}^{-1}$ and were allotted to the stretching vibration of $-\mathrm{OH}$ groups. Greater absorption at $1630 \mathrm{~cm}^{-1}$ (carboxylate groups) and absence or weaker absorption at $1745 \mathrm{~cm}^{-1}$ (ester carbonyl groups) indicated these as low methoxyl pectins.

\subsection{Monosaccharide Composition of Hydrocolloid.} Monosaccharide profiling of fruit fractions of S. indicum, $S$. surattense, and $S$. nigrum hydrocolloid showed the predominant presence of galacturonic acid (GalU), glucuronic acid (Glu), glucose (Glc), galactose (Gal), xylose (Xyl), mannose (man), and arabinose (Ara) (Figure 3). S. indicum fruit was richly constituted of glucose $(8.54 \mu \mathrm{g} / \mathrm{mL})$, galactose $(8.34 \mu \mathrm{g} / \mathrm{mL})$, galacturonic acid $(2.67 \mu \mathrm{g} / \mathrm{mL})$, and arabinose $(1.28 \mu \mathrm{g} / \mathrm{mL})$. Monosaccharide observed in $S$. surattense fruit was glucose, glucuronic acid, and galacturonic acid in order of glucuronic acid $>$ glucose $>$ galacturonic acid, while the xylose, arabinose, and mannose were absent. Fruits of $S$. nigrum consist of glucose $(1.741 \mu \mathrm{g} /$ $\mathrm{mL})$, galacturonic acid $(1.088 \mu \mathrm{g} / \mathrm{mL})$, xylose $(0.284 \mu \mathrm{g} / \mathrm{mL})$, and mannose $(0.390 \mu \mathrm{g} / \mathrm{mL})$. Galactose, glucuronic acid, and arabinose were absent in $S$. nigrum fruit. These findings suggest the higher probability of the presence of three common monosaccharides (glucose, glucuronic acid, and galactose) from different hydrocolloids and also indicated that these convert to fractions through water extraction. Contrarily, the existence of xylose and mannose in minute amounts may be due to less extraction capacity of xylose and mannose through water extraction from their polysaccharides. The low extraction capacity may be elucidated by the fact that mannose and xylose are the main elements of hemicelluloses and are found to be steady and stable to extraction through water. Moreover, it may be also be caused by the tough bonds between cellulose and hemicellulose resulting in problems in bond breakage [24]. However, Eromosele et al. [25] extracted xylose and mannose in higher amounts when strong alkali $(4 \mathrm{M} \mathrm{NaOH})$ was used. Hence, the methods of extraction are critical in obtaining the required and accurate monosaccharide profile and also affect the functional characteristics of the extracted hydrocolloid. Similar to the present study, Cui and Mazza [26] analyzed the different varieties of flaxseed mucilage and found these to contain galacturonic acid, xylose, glucose, galactose, mannose, arabinose, and rhamnose as major sugar constituents.

\section{Conclusion}

Water-soluble hydrocolloids in the aerial parts of S. nigrum, S. surattense, and S. indicum were extracted and characterized. Among fruits, stem, and leaf fractions of investigated plants, the fruits of all plant species showed the best quantity and quality of hydrocolloids. The fruit fractions of S. indicum showed the highest hydrocolloid content with good waterand oil-holding capacities, emulsifying activity, and foaming stability, signifying its use as a foam stabilizer in frothy beverages and in foam-based food products. Reverse-phase HPLC analysis showed glucose, galactose, and galacturonic acid as major sugar components. These findings reveal these hydrocolloids as potential thickening agents, which can be used to modify the texture of food and also as a fat replacer in low-fat food. However, further studies are necessary to achieve more comprehensive characterization and commercial applications.

\section{Data Availability}

The data used to support the findings of the present study are included within the article.

\section{Conflicts of Interest}

The authors declare no conflicts of interest.

\section{Acknowledgments}

The authors are highly thankful to the Government College University, Faisalabad, Pakistan. This work was funded by Researchers Supporting Project number (RSP 2020/26), King Saud University, Riyadh, Saudi Arabia.

\section{References}

[1] S. P. Gannasin, Y. Ramakrishnan, N. M. Adzahan, and K. Muhammad, "Functional and preliminary characterisation of hydrocolloid from tamarillo (Solanum betaceum Cav.) puree," Molecules, vol. 17, no. 6, pp. 6869-6885, 2012.

[2] M. C. Ibañez and C. Ferrero, "Extraction and characterization of the hydrocolloid from Prosopis flexuosa DC seeds," Food Research International, vol. 36, no. 5, pp. 455-460, 2003.

[3] M. Kapoor, D. Khandal, G. Seshadri, S. Aggarwal, and R. K. Khandal, "Novel hydrocolloids: preparation \& applications-a review," IJRRAS, vol. 16, no. 3, pp. 432-482, 2013.

[4] F. D. Boesewinkel and F. Bouman, "The seed: structure and function," in Seed Development and Germination, J. Kigel and 
G. Galili, Eds., pp. 1-24, Marcel Decker, New York, NY, USA, 1995.

[5] W. P. Wu, B. Y. Zhao, Q. Wu, L. S. Chen, and K. A. Hu, "The strengthening effect of guar gum on the yield stress of magnetorheological fluid," Smart Materials and Structures, vol. 15, no. 4, pp. N94-N98, 2006.

[6] Y. Brummer and S. W. Cui, "Detection and determination of polysaccharides in foods," in Food Polysaccharides and Their Applications, A. M. Stephen, G. O. Phillips, and P. A. Williams, Eds., pp. 704-705, CRC Press, Boca Raton, FL, USA, 2006.

[7] V. Rana, P. Rai, A. K. Tiwary, R. S. Singh, J. F. Kennedy, and C. J. Knill, "Modified gums: approaches and applications in drug delivery," Carbohydrate Polymers, vol. 83, no. 3, pp. 1031-1047, 2011.

[8] D. Vipul, G. K. J. Prajapati, G. Naresh, P. Moradiya, P. Narayan, and S. Randeria, "Pharmaceutical applications of various natural gums, mucilages and their modified forms," Carbohydrate Polymers, vol. 92, no. 2, pp. 1685-1699, 2013.

[9] S. S. Turk and S. Reinhold, "Printing properties of a high substituted guar gum and its mixture with alginate," Dyes and Pigments, vol. 47, pp. 269-275, 2000.

[10] AOAC, Official Methods of Analysis, Association of Official Analytical Chemist, Washington, DC, USA, 2005.

[11] J. A. Robertson, F. D. de Monredon, P. Dysseler, F. Guillon, R. Amado, and J.-F. Thibault, "Hydration properties of dietary fibre and resistant starch: a European collaborative study," LWT-Food Science and Technology, vol. 33, no. 2, pp. 72-79, 2000.

[12] C.-F. Chau, P. C. K. Cheung, and Y.-S. Wong, "Functional properties of protein concentrates from three Chinese indigenous legume seeds," Journal of Agricultural and Food Chemistry, vol. 45, no. 7, pp. 2500-2503, 1997.

[13] L. Campbell, V. Raikos, and S. Euston, "Heat stability and emulsifying ability of whole egg and egg yolk as related to heat treatment," Food Hydrocolloids, vol. 19, no. 3, pp. 533-539, 2005.

[14] Y. Lv, X. Yang, Y. Zhao, Y. Ruan, Y. Yang, and Z. Wang, "Separation and quantification of component monosaccharides of the tea polysaccharides from Gynostemma pentaphyllum by HPLC with indirect UV detection," Food Chemistry, vol. 112, no. 3, pp. 742-746, 2009.

[15] O. Yuliarti, K. Goh, L. M. Merino, J. Mawson, L. Drummond, and C. S. Brennan, "Effect of extraction techniques and conditions on the physicochemical properties of the water soluble polysaccharides from gold kiwifruit (Actinidia chinensis)," International Journal of Food Science and Technology, vol. 43, no. 12, pp. 2268-2273, 2005.

[16] H. Karazhiyan, S. M. A. Razavi, and G. O. Phillips, "Extraction optimization of a hydrocolloid extract from cress seed (Lepidium sativum) using response surface methodology," Food Hydrocolloids, vol. 25, no. 5, pp. 915-920, 2011.

[17] J. A. L. da Silva and M. P. Goncalves, "Studies on a purification method for locust bean gum by precipitation with isopropanol," Food Hydrocolloids, vol. 4, no. 4, pp. 277-287, 1990.

[18] P. R. P. Verma and B. Razdan, "Studies on Leucaena leucocephala seed gum: evaluation of suspending properties," S.T.P. Pharma Sciences, vol. 11, no. 4, pp. 289-293, 2012.

[19] D. K. Sandrou and I. S. Arvanitoyannis, "Low-fat/calorie foods: current state and perspectives," Critical Reviews in Food Science and Nutrition, vol. 40, no. 5, pp. 427-447, 2010.

[20] M. S. Brewer, "Reducing the fat content in ground beef without sacrificing quality: a review," Meat Science, vol. 91, no. 4, pp. 385-395, 2012.
[21] Y. Kishk, "Optimization of isolation flaxseed mucilage from methanolic extract and its functional characteristics," Journal of Food and Dairy Sciences, vol. 4, no. 10, pp. 539-556, 2013.

[22] V.-O. Alfredo, R.-R. Gabriel, C.-G. Luis, and B.-A. David, "Physicochemical properties of a fibrous fraction from chia (Salvia hispanica L.)," LWT-Food Science and Technology, vol. 42, no. 1, pp. 168-173, 2009.

[23] R. Noreen, C.-C. Chien, M. Delugin et al., "Detection of collagens in brain tumors based on FTIR imaging and chemometrics," Analytical and Bioanalytical Chemistry, vol. 401, no. 3, pp. 845-852, 2011.

[24] T. C. Ramirez, P. Esquivela, and R. Carleb, "Neutral sugar profile of cell wall polysaccharides of pitaya fruits," Carbohydrate Polymers, vol. 83, no. 3, pp. 1134-1138, 2011.

[25] C. O. Eromosele, L. A. Arogundade, I. C. Eromosele, and O. Ademuyiwa, "Extractability of African yam bean (Sphenostylis stenocarpa) protein in acid, salt and alkaline aqueous media," Food Hydrocolloids, vol. 22, no. 8, pp. 1622-1628, 2008.

[26] W. Cui and G. Mazza, "Physicochemical characteristics of flaxseed gum," Food Research International, vol. 29, no. 3-4, pp. 397-402, 1996. 